\title{
Una escocesa enamorada de México: la obra de Madame Fanny Calderón de la Barca*
}

\section{Resumen}

La vida en México, obra de Madame Fanny Calderón de la Barca, es un texto esencial para el conocimiento del México del siglo XIX, particularmente entre los años 1840 y 1841. Su riqueza radica, además de las descripciones de primera mano por parte de su atura, de los paisajes, sitios, personajes, costumbres y alimentos, en ser la primera obra de literatura de viajes del país escrita por una mujer. El texto, además, posee el mérito de haber trascendido pese a las dificultades experimentadas por la autora como mujer en una época y en un lugar en el que no se le daba crédito a su género y por los vaivenes de la política, tanto en México, como en España y Estados Unidos, países donde residió, así por el notable ejercicio de comprensión de un mundo opuesto a ella.

\section{Palabras clave}

Tesauro: México.

Autor: literatura de viajes, escritura de mujeres, siglo XIX.

Referencia bibliográfica para citar este artículo: Esparza Ramírez, Juan Carlos. "Una escocesa enamorada de México: la obra de Madame Fanny Calderón de la Barca”. Anuario de Historia Regional y de las Fronteras 26.2 (2021): 165-185.

Juan Carlos Esparza Ramírez: Magister en Historia de México. Licenciado en Ciencias de la Cultura por la Universidad Pontificia de México. Coordinador académico de Opus Artis. Arte que trasciende. Correo electrónico: juancarlos_esparza@yahoo.com. Código ORCID: 0000-0001-8557-000X.

Fecha de recepción:19/10/2020

Fecha de aceptación: 9/02/2021

\footnotetext{
*El interés por la obra "La vida en México", de la Marquesa Calderón de la Barca tiene raíces distintas: una personal y otra académica. En primer lugar, esta obra llegó a mis manos en mis años universitarios durante la convalecencia de un familiar muy querido. Los relatos de la autora acompañaron aquellas horas de cuidados en el hospital hasta la afortunada recuperación de dicha persona.

Más adelante, ya en el momento de la elaboración de la tesis de maestría en Historia de México, el testimonio de la Marquesa constituyó una de las fuentes primarias sobre el evento que analicé: el pronunciamiento federalista del 15 de julio de 1840 en la Ciudad de México.

Entre una y otra etapa de mi formación, mi interés por el siglo XIX mexicano, particularmente por la primera mitad, periodo poco abordado, he trabajado desde distintas perspectivas la visión de mujer, extranjera, viajera y, hasta cierto punto, diplomática, de la autora, ya que la obra es reconocida en el país como la primera de su especie en retratar a ras de suelo, las costumbres, tradiciones y vivencias de aquel México.
} 


\title{
A Scotswoman in Love with Mexico: the Work of Madame Fanny Calderón de la Barca
}

\begin{abstract}
Life in Mexico, by Madame Fanny Calderón de la Barca, is an essential text for understanding Nineteenth-century Mexico, particularly between the years 1840 and 1841. Its richness consists of being the first work of travel literature in the country written by a woman additionally to the first-hand descriptions of landscapes, places, characters, customs, and food. The text also has the merit of having transcended despite the difficulties experienced by the author as a woman at a time and in a place where her gender was not given credit and due to the ups and downs of politics, both in Mexico as in Spain and the United States, countries where she lived, as well as due to the remarkable exercise of understanding a world opposed to her.
\end{abstract}

\section{Keywords}

Thesauri: Mexico.

Author: Travel Literature, Women's Writing, Nineteenth-Century.

\section{Uma escocesa apaixonada pelo México: a obra de Madame Fanny Calderón de la Barca}

\section{Resumo}

A vida no México, obra de Madame Fanny Calderón de la Barca, é um texto essencial para a compreensão do México do século XIX, principalmente entre os anos 1840 e 1841. Sua riqueza reside, além das descrições de primeira mão de sua autora, de paisagens, lugares, personagens, costumes e cozinha, por ser a primeira obra de literatura de viagem do país escrita por uma mulher. O texto também tem o mérito de ter transcendido apesar das dificuldades vividas pela autora como mulher em uma época e lugar onde seu gênero não era valorizado e pelos altos e baixos da política, tanto no México, quanto na Espanha. e os Estados Unidos, países onde viveu, também pelo notável exercício de compreensão de um mundo oposto a ela.

Palavras-chave

Tesauro: México.

Autor: literatura de viagem, escrita feminina, século 19. 


\section{Viajera y escritora}

Si el siglo XIX es pródigo en autoras de narrativa, lo es también en relatos de viajes escritos por "ellas" [...] Una significativa cantidad de diarios, memorias, cartas e incluso novelas, incorporan discursos vertebrados por las trayectorias,

las escalas, y no pocas veces, por la imaginación de quienes los producen. ${ }^{1}$

Dentro de la literatura de viajes en el México del siglo XIX, pocas obras han alcanzado tanta relevancia como La Vida en México durante una residencia de dos años en ese país, de Frances Erskine Inglis, más conocida por el apellido de su esposo como Madame Fanny Calderón de la Barca, el marqués Ángel Calderón de la Barca, primer ministro plenipotenciario de España en México, aunque en el recuerdo tan importante diplomático haya quedado a su sombra. ${ }^{2}$ Esta obra relata en primera persona y con visión íntima y emotiva, pero también erudita, los pormenores de la estancia y recorrido por el Altiplano Central de México durante la estancia de la pareja entre los años 1840 y 1841. Se trata de uno de los primeros registros presenciales y contemporáneos no solo de personajes, eventos, lugares y costumbres, sino también, la primera mirada femenina plasmada por escrito en el siglo XIX sobre aquel joven país y sus habitantes quienes, hasta entonces, no habían sido retratados más que por curiosidad científica, pintoresca o de manera despectiva por el ojo del viajero europeo. ${ }^{3}$

Frances Erskine Inglis nació en Edimburgo, Escocia, 23 de diciembre de 1804. Desde joven comenzó a recorrer otras tierras, ya que su padre, abogado de profesión, cayó en la ruina al ser arrastrado por las deudas de un aristócrata insolvente que le tenía como fiador y por ello, la familia debió huir hacia el puerto de Boulogne, Francia, destino común de los deudores británicos. ${ }^{4}$ Tras el fallecimiento del padre en 1830, la viuda cruzó el Atlántico con sus hijas para establecerse en Boston, Estados Unidos, donde para sobrevivir fundó un colegio para señoritas que al fin volvió a traer la prosperidad familiar, así como el ascenso económico y social.

Fue precisamente este nuevo ambiente el que contribuyó que la joven "Fanny", como siempre fue llamada, se rodeara de distinguidas amistades del mundo

\footnotetext{
${ }^{1}$ Norma Alloatti, Narradoras de la ventura: viajeras del siglo XIX en la colección Lermon, Revista Electrónica de Fuentes y Archivos (Córdoba, Centro de Estudios Históricos "Prof. Carlos S. A. Segreti" año 5, número 5, 2014), 53.

${ }^{2}$ Felipe Teixidor, Prólogo a Madame Calderón de la Barca, La vida en México durante una residencia de dos años en ese país (México, Editorial Porrúa, colección "Sepan cuantos...” Núm. 74), XXII.

${ }^{3}$ En este sentido, las obra México en 1827, del primer ministro plenipotenciario del Reino Unido en México, Henry George Ward, se centra en la descripción geográfica en miras a que los futuros súbditos británicos que arribasen, aprovecharan los beneficios de la minería, "pero mientras Henry Ward utilizaba la palabra para retener sus impresiones, [su esposa] se valía del dibujo [pues] El libro [...] incluyó trece litografías basadas en dibujos de Emily [Swinburne]. Estas representaciones fueron no sólo reconocidas, sino también fuente de inspiración para futuros viajeros, como la marquesa Calderón de la Barca y los pintores alemanes Carl Nebel y de Johann Moritz Rugendas. Gisela von Wobeser, Testimonios escritos y pictóricos de viajeras extranjeras. México. Siglo XIX en Sara Beatriz Guardia (Edición y compilación) en Viajeras entre dos mundos, (Mato Grosso do sul, Universidade Federal da Grande Dourados, 2012), 214-215.
}

${ }^{4}$ Teixidor, XV. 
de la cultura, prestigiosos historiadores hispanistas, George Ticknor, y William Prescott; relaciones que, por así decirlo, significaron su puerta de entrada un universo diametralmente opuesto al de su cultura anglosajona de origen. Fue justamente en casa de Prescott donde en 1838 conocería a su futuro esposo, el marqués Ángel Calderón de la Barca, ${ }^{5}$ representante diplomático de España en los Estados Unidos; ese mismo año contraerían matrimonio. No obstante, la diferencia de edades y credos religiosos, pues ella pertenecía a la comunión episcopal.

A mediados de 1839, Don Ángel recibió de su gobierno el nombramiento como ministro plenipotenciario para México, tras el reconocimiento tardío de la independencia de ese país a finales de $1836^{6}$ y embarcaron desde Nueva York para dirigirse al puerto de Veracruz. Durante esta travesía y a lo largo de los dos años siguientes Fanny comenzó la redacción de su obra La vida en México. Se trata un compendio de cincuenta y cuatro cartas dirigidas a su familia en Boston en las que se narra con suma gracia y detalle los pormenores del trayecto, el encuentro con la naturaleza y la cultura mexicana y la relación con los personajes más prominentes de la escena social y política del país. Sus impresiones sobre México, siempre moderadas y hasta comprensivas, estuvieron destinadas, al menos en su inicio, al entorno familiar y contrastan con las vertidas en la correspondencia de su marido, quien veía en México a un país caótico: "si siguen destrozándose así, retrocederán a su primitiva barbarie".?

Al final de la misión diplomática del Marqués, partieron para España con una escala necesaria en Estados Unidos para aguardar tiempos políticos más favorables para su carrera, ya que en su país el militarismo provocaba en ese tiempo tantos cambios de gobierno como lo que criticaba de México $^{8}$ y para ese entonces, era mal visto por el gobierno en turno por su trayectoria como funcionario de los tiempos de Fernando VII. Finalmente, con trabajos logró obtener el nombramiento de una gestión que ya había desempeñado: nuevamente embajador en Estados Unidos de 1844 y 1853.

Entre 1846 y 1848 tuvo lugar la injusta invasión estadounidense a México, situación que ocasionaría a la pareja un hondo pesar, tanto por la cercanía cultural y

\footnotetext{
${ }^{5}$ Raúl Figueroa, Ángel Calderón de la Barca, diplomático español (1790-1861). Notas biográficas, Estudios. Filosofía-Historia-Letras, Instituto Tecnológico Autónomo de México. http://biblioteca.itam.mx/estudios/ estudio/letras22/notas1/sec_1.html Don Ángel "era un criollo de familia acomodada nacido en Buenos Aires, en 1790, donde contribuyó a la defensa de este puerto contra la invasión de los ingleses en 1806. Se traslada a la península y durante la guerra de la independencia española, cayó prisionero de los franceses. Adoptó como patria la que había sido la de sus padres [con un] nacionalismo doliente y exasperado ante la pérdida del imperio colonial que sufrió España y que él presenció y vivió en carne propia”. Hizo carrera diplomática en Rusia e Inglaterra e ideológicamente era un monárquico convencido.

${ }^{6}$ El Tratado Santa María-Calatrava, celebrado en Madrid el 28 de diciembre de 1836 puso fin a las hostilidades de la Corona española hacia México, la cual, sólo hasta la muerte del rey Fernando VII en 1833, aceptó iniciar los acercamientos diplomáticos con la que antes fuera su más rica posesión americana.

${ }^{7}$ Figueroa.

${ }^{8}$ Charles Esadile, El levantamiento español, en La quiebra del liberalismo (1808-1939) (Barcelona, Crítica, 2001), 84-90. El prestigioso general Baldomero Espartero forzó la disolución de las Cortes y se puso al frente de las revueltas contra la reina regente María Cristina, a quien obligó a cederle la tutela de la reina niña Isabel II y partir al exilio.
} 
espiritual, como por los gratos recuerdos de aquel país. En Washington conocieron al político y escritor yucateco Justo Sierra O'Reilly, ${ }^{9}$ quien es uno de los pocos autores que relatan en sus escritos el recuerdo de Fanny. De sus Impresiones sobresale la buena relación que llevaba con el matrimonio Calderón de la Barca y el pesar de la pareja por los acontecimientos en México:

Pero, paisano -no cesaba de exclamar don Ángel-, jes posible que los yanquees hayan plantado el pabellón de las estrellas hasta en el Palacio de los Virreyes de México!” Era, en efecto, una cosa inexplicable para el señor Calderón [de la Barca], y aún creo para todo el mundo, aquella especie de sacrilegio que él veía en la profanación del Palacio de los Virreyes. Yo confieso que el accidente de haber sido ese Palacio de los virreyes españoles, no era para mí lo que hacía más odioso el caso de la profanación. ${ }^{10}$

De estos años, más del triple de los pasados en México, la autora apenas dejó esta impresión: "Washington es una ciudad aburrida, fea y sucia ¿qué puede escribirles?". ${ }^{11}$ En 1847 la tragedia ensombreció su vida por la muerte de su madre en un incendio y será también en estas fechas que adopte completamente la fe católica. Tampoco hay mucho margen para cultivar las antiguas relaciones, pues sus hermanas ya residían en Baltimore y sus viejos amigos y mentores intelectuales, Ticknor y Prescott, en Boston.

En 1853 el Marqués fue llamado a España a formar parte del Consejo de Ministros y, de vuelta en Madrid, Fanny gozó de las bondades de la vida cultural: teatro actual y del Siglo de Oro, zarzuelas, óperas. De esos recuerdos se conformó su nueva obra, The Attaché in Madrid; or, Sketches of the Court of Isabella II, la cual, sin embargo, tuvo poco éxito editorial debido a las revoluciones de 1854 y por haber sido publicada de manera anónima en inglés. ${ }^{12}$ A causa de la revuelta, el Marqués debió huir disfrazado hacia Francia, donde fueron recibidos por los emperadores en virtud de su amistad con la familia de Eugenia de Montijo.

\footnotetext{
${ }^{9}$ Justo Sierra O’Reilly (1814-1861) Escritor y político mexicano. Director de los periódicos El Museo Yucateco (1841-1842), Registro Yucateco (1845-1849), El Fénix (1848-1851) y La Unión Liberal (18551857), escribió algunas novelas por entregas: El filibustero (1841), Un año en el hospital de San Lázaro (1845-1846). Es autor también de crónicas de viajes (Impresiones de un viaje a los Estados Unidos de América y al Canadá, 1851) y de estudios históricos (Los indios de Yucatán, 1857). Sierra O'Reilly fue el encargado de negociar ante el gobierno de los Estados Unidos el cese de hostilidades en la Península de Yucatán durante la invasión a México de 1847 a cambio de la neutralidad en la guerra de esa parte del territorio. José Palomar de Miguel, Diccionario de México, (México, Editorial Trillas, 2005), 1231.

${ }^{10}$ Teixidor XXXIX.

${ }^{11}$ Teixidor XXVII.

${ }^{12}$ Oscar Flores, Frances Erskine Inglis (Madame Calderón de la Barca). The Attaché in Madrid; or, Sketches of the Court of Isabella II. Traslated from German, (Nueva York, Casa Appleton, 1856). http:// ocw.udem.edu.mx/cursos-de-profesional/historia-del-mexico-independiente/08calderondelabarca.pdf El libro se dio a conocer como las supuestas cartas traducidas al inglés de un joven alemán. María Bono López, Frances Erskine Inglis Calderón de la Barca y el Mundo Indígena Mexicano, en Manuel Ferrer Muños (coordinador), La imagen del México decimonónico de los visitantes extranjeros: ¿un Estadonación o un mosaico plurinacional? (México, Universidad Nacional Autónoma de México, 2002), https:// archivos.juridicas.unam.mx/www/bjv/libros/1/252/8.pdf
} 
De regreso a España, mudaron su residencia a Zarzauz, en el País Vasco, donde vivieron gracias a la pensión del Marqués hasta su muerte en 1861. Sin hijos ni familia, Fanny se retiró a un convento en Anglet, en las cercanías de Biarritz, pero, al poco tiempo la reina Isabel II, en virtud de los servicios prestados en vida por su esposo, así como por su propia fama de bondadosa y culta, la llamó al Palacio Real en Madrid como institutriz de la infanta Isabel Francisca de Borbón. La Revolución Gloriosa de 1868 puso fin al reinado de Isabel II y la familia real partió al exilio a Francia, Fanny compartió el destierro y solo regresaría hasta 1874, cuando se restauró monarquía. Siempre fiel a su encargo de tutora de la infanta, su hermano, el nuevo monarca, Alfonso XII, al cabo de dos años le extendería el título de Marquesa que en vida ostentara su esposo. Finalmente, murió en el Palacio Real de Madrid en 1882. ${ }^{13}$

\section{La vida en México y sus ediciones}

Sorprende que una obra de tal riqueza haya tenido tan pocas ediciones. La explicación más plausible sería que la propia autora desistió de continuar con el asunto, aunque, en su momento, algunas cartas fueron publicadas en periódicos mexicanos como El siglo diez y nueve y El Liceo Mexicano a partir de traducciones de la edición norteamericana.

Las principales ediciones fueron: Life in México during a Residence of Two Years in That Country. By Mme. C. de la B. In Two Volumes. Boston, Charles C. Litte and James Brown, 1843, con una segunda edición también en Boston el mismo año. Igualmente, en 1843 se publicó en Londres en un solo volumen bajo el mismo título, pero con la variante de Madame, por Mme., y con el pie de imprenta London: Chapman and may, 186, Strand, 1843; también se reeditó en Belfast, Irlanda, en 1852. Felipe Texidor, traductor e introductor de la edición mexicana de Porrúa de 1959 y posteriormente para la de la Colección "Sepan Cuantos..." en 1967 señala que:

En México pertenece a don Manuel Romero de Terreros, marqués de San Francisco, el mérito de haber sido el primero en presentar al público de habla española la figura de la señora Calderón de la Barca, proporcionándole un horizonte más amplio; ligándola al mundo en el cual vivió y a las condiciones del país, cuando éste apenas cumplía, en política, la mayoría de edad. Publicó su trabajo al frente de la primera traducción al español de La vida en México, hecha por don Enrique Martínez Sobral, de la Real Academia Española, editada por Bouret en 1920. Cúpole también al señor marqués de San Francisco el honor de prolongar [sic] en inglés una edición londinense. Imposible citar aquí los principales artículos aparecidos después en periódicos y revistas, o las opiniones manifestadas incidentemente en libros. ${ }^{14}$

Otra edición, aunque parcial, fue la coordinada por Antonio Acevedo Escobedo en 1944, a cargo de la Secretaría de Educación Pública, tomada de la traducción de 1920, y al año siguiente, la reedición de ésta por la Editorial Hispanomexicana. En 1971, nuevamente la SEP editó para su colección "Cuadernos

\footnotetext{
${ }^{13}$ Teixidor XXXII-XXXV

${ }^{14}$ Teixidor XIII-XIV.
} 
Mexicanos" una selección de cartas reunidas bajo el título Recorrido por Michoacán en 1841, tomadas de la edición de Teixidor de 1959 y, finalmente, en 1976 la editorial Porrúa publicó la obra íntegra en dos volúmenes. Ya en el siglo XXI, dos ediciones de la obra son las que destacan, una española condensada y de lujo de 2009 a cargo del Centro de Estudios Reprográficos y Real de Catorce Ediciones, y en México en 2010, la igualmente condensada edición bajo el título de La vida en el México independiente de Jennifer Clement y Susan Chapman de The Anglo Mexican Foundation, patrocinada por British Petroleum. ${ }^{15}$

\section{Recepción y percepción de la obra}

La vida de la Marquesa de Calderón de la Barca estuvo ligada al papel de esposa de diplomático, por ello, poco se sabe de alguna actividad personal independiente; esto tiene una razón de ser de acuerdo a los parámetros mentales y culturales de la época, primeramente, porque "Hasta el siglo XIX las mujeres que aparecen en el discurso histórico son generalmente mujeres excepcionales, sea por sus virtudes, heroísmo o belleza", ${ }^{16}$ pero también:

Ya que las mujeres han sido excluidas del terreno de la historia monumental escrita mayormente por los hombres, se les ha negado también su contribución al campo de la historiografía americana. El aporte femenino al discurso nacionalista se ha dado cuantitativamente en términos de géneros literarios considerados "menores", como la carta, el relato íntimo, la memoria o el relato de viajes. Asimismo, las historias escritas por mujeres han sido o bien relegadas a los márgenes de la tradición, o bien excluidas del recuento histórico del nacionalismo hispanoamericano. ${ }^{17}$

Pese a su moderación con respecto a los eventos políticos que presenció, en virtud de no comprometer la labor diplomática de su marido ni la postura oficial del gobierno que representaba, en México su libro causó revuelo entre sus lectores contemporáneos, quienes la criticaron de frivolidad, de exageración, de supuestas calumnias a los próceres, particularmente sobre el general Guadalupe Victoria, primer presidente de México, de desacato al compromiso de mantener una actitud reservada, traicionando así la confianza de Don Ángel y del país que la había acogido. ${ }^{18}$

El desprecio de los nacionales a la obra de los viajeros extranjeros parece haber sido una constante tanto en España como en México, lo que explica en parte la fortaleza del género costumbrista en la literatura decimonónica, pues en palabras de su principal exponente en la Península Ibérica, Ramón Mesonero Romanos, la

\footnotetext{
${ }^{15}$ Clement, (2010).

${ }^{16}$ Guardia, Sara Beatriz, Un acercamiento a la historia de las mujeres (Monterrey, Revista de Humanidades núm. 10, Instituto Tecnológico y de Estudios Superiores de Monterrey, 2001) 109-119. https://www. redalyc.org/articulo.oa?id=38401005

${ }^{17}$ Adriana Méndez Rodenas, Género e historiografia en "La Vida en México" (1843), en CiberLetras: revista de crítica literaria y de cultura, 5, (2002) http://www.lehman.cuny.edu/ciberletras/v05/mendez.html.

${ }_{18}$ Principalmente los escritores Luis Martínez de Castro, Manuel Payno e Ignacio Manuel Altamirano, Teixidor, IX-X.
} 
misión estas obras la de vengar "al carácter nacional de los desmedidos insultos, de las extravagantes caricaturas en que le han presentado sus antagonistas", quienes no eran otros que los viajeros románticos. ${ }^{19}$

La autora, al parecer, nunca estuvo enterada de las reacciones que en México ocasionó su obra, sin embargo, era conocida su elusión al tema; relata el político y escritor yucateco Justo Sierra O’Reilly: "No sé yo si se habrá arrepentido de ciertos golpes dados en ese cuadro que hizo sobre México; lo que puedo afirmar es que no le gusta mucho que se hagan alusiones a su libro, y evita la ocasión de hablar de él", ${ }^{20}$ Ya sea por la incomodad generada o por la visión de las mujeres en el siglo XIX, las personalidades que le conocieron no hacen mayor referencia de ella: "de su belleza nadie dice una sola palabra, solo se pondera su cultura, el ingenio y la exquisita educación". ${ }^{21}$

Ya se ha hablado de las influencias de dos grandes hispanistas norteamericanos, Ticknor y Preston, quienes contribuyeron a la formación de su avidez por el conocimiento, pero ¿qué antecedentes literarios e históricos tenía Fanny sobre México antes de pisar sus tierras por primera vez? Una prosa ejercitada como la suya provenía de haber ensayado ya el género novelesco con la temprana publicación de The ofended one: conocía, además, los textos básicos de todo viajero: las Cartas de Relación del conquistador Hernán Cortés, la Historia Antigua de México del padre jesuita Francisco Xavier Clavijero y el Ensayo político sobre el reino de la Nueva España del explorador alemán, el barón Alexander von Humboldt; y una vez en el país se serviría de las obras de políticos connotados como el Ensayo histórico de las revoluciones de México de Lorenzo de Zavala y México y sus revoluciones, de José María Luis Mora, así como de revistas y calendarios. ${ }^{22}$

El mundo que describe la autora de La vida en México es no es principalmente el del medio vinculado a la labor de su marido: la aristocracia y la clase política mexicana, aunque sí llega a hacer breves menciones de ello; Fanny “prefiere a la vida de la sociedad, la vida al aire libre; contemplar el paisaje y escudriñar a quienes viven en él", ${ }^{23}$ es además sensible a todas las manifestaciones de la belleza,

Deseosa de encontrarla en todas las cosas, alcanzó el estado de gracia, o sea el amor, para describir en la naturaleza de México la esencia escondida. Gustará de la belleza en el deslumbre de un amanecer, y en la opulencia de los colores que deja en las nubes el sol poniente; y en lo ameno, por pintoresco, en donde no estorba un escrúpulo de romanticismo, no disminuye la realidad de la escena un ápice y la gracia y la frescura permanecen en ella para siempre. ${ }^{24}$

\footnotetext{
${ }_{19}$ Ramón Mesonero Romanos, Cartas Españolas, en José Escobar Arronis, «El Curioso Parlante» en «La Revista Española»: retrato del autor, http://www.cervantesvirtual.com/servlet/SirveObr as/12371069778018296310624/p0000001.htm\#I_0_

${ }^{20}$ Teixidor XXI.

${ }^{21}$ Teixidor XXII.

${ }^{22}$ Teixidor XXXIX.

${ }^{23}$ Teixidor LIII.

${ }^{24}$ Teixidor LIX.
} 
Contrariamente a la mayoría de los actores políticos y sociales de esa época, sus opiniones sobre el poblador originario de México, el indio, su tono es moderado: "Si en alguno de los retratos que les hace pudo írsele la mano en las máculas, no falta nunca una palabra dulce para atenuarlas. Y en estos encuentros, rebasando el interés anecdótico, dejará grabado en la fantasía del lector un recuerdo siempre amable y poético". ${ }^{25}$

Más allá de la descripción testimonial de la cotidianidad de México, de levantamientos armados, de conflictos económicos como la crisis del cobre y los abruptos cambios de presidente. Esta obra es la más profusa y rica para conocer aspectos naturales y sociales como el paisaje, la vestimenta, la música y la cocina del México que apenas daba sus primeros pasos, pero, además, "es asimismo la fuente importante para el estudio de diversas ramas de la historia, como la de la vida cotidiana, de las mentalidades, de la mujer, de la familia y de las costumbres, entre otros". ${ }^{26}$ Sin embargo, el aspecto más interesante de su prosa

Es el hecho de que pudo contar lo que ocurría en el silencioso mundo de las mujeres mexicanas: en la alta sociedad, en el círculo íntimo y vivo de las sirvientas y, especialmente, en el ámbito secreto de las monjas católicas. Las vidas de estas últimas mujeres eran historias que ningún hombre podría haber contado. Sus descripciones de muchachas jóvenes relegadas a la Iglesia son dolorosas y críticas. Fanny sabía lo que era hablar a las religiosas atrás de sus muros de hierro forjado, sin poder verlas. Cuando habla de ellas se refiere a su presencia como 'la voz", ${ }^{27}$

\section{EI México de 1840}

Los procesos de construcción de los estados nacionales en el siglo XIX son sumamente complejos, ello por la diversidad de acontecimientos derivados del rápido reacomodo geopolítico y el protagonismo de los personajes emergentes que van moldeando la política nacional al ritmo de sus propias andanzas. En el ámbito internacional,

México surgió como nación en el momento en que se construía el nuevo orden internacional posterior a las guerras napoleónicas. [...] Las grandes potencias [...] bajo sus sistemas monárquicos, se mostraron "legitimistas" y, por lo tanto, refractarias al liberalismo y a los nacionalismos; esto afectó la aceptación de los nuevos países americanos. ${ }^{28}$

\footnotetext{
${ }^{25}$ Teixidor LXI.

${ }^{26}$ Wobeser 218

${ }^{27}$ Jennifer Clement, Compilan cartas de una perspicaz escocesa que describió el México independiente, http://www.jornada.unam.mx/2010/05/25/index.php?section=cultura\&article=a08n1cul (2010).

${ }^{28}$ Rafael Rojas, La nueva nación ante el mundo, en Gran Historia de México Ilustrada, Tomo III: El Nacimiento de México, 1750-1856, (México, Planeta DeAgostini, CONACULTA, INAH, 2002): 202.
} 
Esta situación colocó a la naciente república, como lo expone la Dra. Josefina Zoraida Vázquez, en el papel de "el país más amenazado del continente". ${ }^{29}$ En lo interior, el México al que llegan los señores Calderón de la Barca corresponde a una época en la que se desarrolló un alto grado de militarismo en buena parte del mundo hispanoamericano decimonónico, periodo que se caracteriza por

el espíritu de rebelión, el deseo de avasallarlo todo, el apetito inmoderado de condecoraciones y ascensos, el empeño de hacerse rico en pocos días, el complejo napoleónico, fueron los vicios característicos del soldado privilegiado y el origen más fecundo de los desórdenes sociales de la república mexicana. ${ }^{30}$

Este México es también en lo social, el de la hegemonía de la clase criolla que sobrevivió a la Guerra de Independencia y que busca su lugar en la nueva república, pero que no logra aún conciliar las añejas tradiciones y modos del virreinato con los acelerados cambios de la época del progreso; este México conserva, aunque ya sin la nomenclatura anterior del sistema de castas, la división social y los privilegios de clase acostumbrados. Es, pues, un país independiente políticamente de España, su antigua metrópoli, pero aun fuertemente ligado a sus antiguas tradiciones. Estas contradicciones internas son las que le volverán altamente vulnerable en su vida política interna y frente a las potencias europeas y el vecino del norte.

A pesar de la agitación permanente de esos años, el sentimiento de orgullo nacional y patriotismo, así como de lealtad regional, marchaba imparablemente en todas las latitudes, propiciado desde la derrota definitiva de los españoles en $1829 ;{ }^{31}$ aunado a ello, aquella generación experimentó una apertura política inspirada en la ilustración y el republicanismo norteamericano; varios de ellos testigos y partícipes del liberalismo español de 1812 y $1820 .{ }^{32}$ Dentro de este complicado país, Fanny Calderón de la Barca encontró, sin embargo, la belleza del paisaje y el patrimonio material, la gracia del folklore local, la firmeza de las tradiciones y la calidez de los mexicanos comunes.

\section{El entorno diplomático mexicano}

Tarde para la vida diplomática, llegó don Ángel Calderón de la Barca junto con su distinguida esposa. México ya había entablado relaciones con otras naciones con las que ya se gozaba de importantes beneficios diplomáticos y comerciales. El país distaba mucho de gozar de la estabilidad social, económica y política que esperaban sus habitantes a raíz de la Independencia, pues, en las primeras tres décadas de vida independiente México había ensayado igual número de formas de gobierno:

\footnotetext{
${ }_{29}$ Josefina Zoraida Vázquez, Los primeros tropiezos, en Historia General de México. Versión 2000, (México, El Colegio de México, 2009): 570.

${ }^{30}$ Manuel Fernández de Velasco, El militarismo en la vida del mexicano hasta 1855, en Estudios de Historia Moderna y Contemporánea de México, (México, Universidad Nacional Autónoma de México, Instituto de Investigaciones Históricas, v. 2, 1967). http://www.iih.unam.mx/moderna/ehmc/ehmc02/008.html

${ }^{31}$ Michael P. Costeloe, La República central en México, 1835-1847. “Hombres de bien” en la época de Santa Anna, (México, Fondo de Cultura Económica, 2000) 26.

${ }^{32}$ Costeloe 31 .
} 
el efímero Primer Imperio (1822-1823), la República Federal (1824-1835) y la República Central (1835-1847).

Desde el punto de vista de los conflictos internacionales, México había sufrido las invasiones extranjeras de España (Expedición de Reconquista, 1829), Francia ("Guerra de los Pasteles", 1838-1839), y graves pérdidas territoriales (Guerra de Texas, 1836, invasión estadounidense, 1846-1848), así como un creciente número de asonadas militares, golpes de estado y revoluciones locales. En el campo diplomático la situación apenas se iba construyendo y, pese a las buenas intenciones, nada estaba asegurado, pues la joven república se encontraba necesitada del reconocimiento internacional.

Con respecto a España, el tardío reconocimiento a la Independencia, ocurrido solo tras la muerte de Fernando VII, caló hondo en el sentir de los mexicanos, lo que abonó el ya existente antihispanismo ${ }^{33}$ generado por los once años de lucha emancipadora y por la continuidad de las hostilidades mediante bombardeos y bloqueos al puerto de Veracruz por el gobierno militar del fuerte de San Juan de Ulúa hasta su captura en 1825 gracias a la flota adquirida con el empréstito inglés, las conspiraciones e intentos de reconquista en 1827 y 1829 , respectivamente. ${ }^{34}$

Las primeras conversaciones directas sobre el asunto del reconocimiento comenzaron en mayo de 1834, una vez muerto el rey Fernando VII y bajo un nuevo régimen liberal. Gracias estos signos de distensión, a finales de 1836 pudo firmarse

\footnotetext{
${ }^{33}$ El efímero Primer Imperio Mexicano (1822-1823) no fue capaz de sostener las Tres Garantías del Plan de Iguala y los Tratados de Córdoba (1821) que deberían ser los pilares del México independiente: Religión Católica, Unión entre americanos y españoles e Independencia de cualquier nación. Aunado al emponzoñamiento del ambiente político nacional generando por Pointsett contribuyeron también otros factores históricos como el descubrimiento de la conspiración del sacerdote español Joaquín Arenas, fusilado por tramar un movimiento para regresar al dominio español y la inmediatamente posterior expulsión de los españoles en 1827. Dos años más tarde la expedición de Reconquista dirigida por el Brigadier Isidro Barradas fue vencida en Tampico en 1829 por Antonio López de Santa Anna. Las pretensiones de la Santa Alianza para restaurar el Antiguo Régimen en Europa fueron bien conocidas en México, aunque no llegaron a afectarle directamente. En España Fernando VII siempre se negó a reconocer la Independencia de México y sólo tras su muerte la reina regente María Cristina entabló relaciones diplomáticas hasta 1836, sin embargo, el primer representante diplomático no llegaría a México sino hasta finales de 1839. España era para aquel México, salvo para las élites del partido conservador, un país desprestigiado en todas las formas posibles. España por su parte, pretendía imponer una idea de románica de raza "como de defensa, un arma para sentirse y pensarse por encima de esa sociedad que frecuentemente les era hostil", ya que perdido el continente americano al menos lucharía por preservar frente a la amenaza anglosajona su herencia: lengua castellana y la religión católica. El reiterado discurso de superioridad cultural y espiritual en la política y la prensa española tampoco allanó el camino hacia el entendimiento. Esto puede verse con amplitud en Romana Falcón, Las rasgaduras de la descolonización, (México, El Colegio de México, 1996) 20.

${ }^{34}$ Las principales expulsiones de españoles en México se dieron en 1827, 1829 y 1833, "una expresión hispanófoba que no tuvo semejante en América Latina [...] En el México del siglo XIX bastaba ser español para convertirse ipso facto en sospechoso: sospechoso de ser un conspirador, un explotador, un ambicioso. En buena medida esta forma de concebir al español era el resultado de una visión histórica de la época colonial. Construida desde el siglo XIX en el contexto de la guerra de independencia, esta interpretación fue extendiéndose, al expresarse en obras historiográficas, en libros de texto, en la prensa y en los discursos cívicos”. Marco Antonio Landavazo, Imaginarios encontrados: El antiespañolismo en los siglos XIX y XX, Tzintzuntzan. Revista de Estudios Históricos, (Morelia, Universidad Michoacana de San Nicolás de Hidalgo, No. 42: julio-diciembre de 2005) 35, 37-38.
} 
el Tratado de Paz y Amistad entre ambos países. Sería entonces el Marqués, por ese tiempo embajador en Estados Unidos, recibiría la encomienda de fungir como el primer ministro plenipotenciario español en México. Contra las expectativas, el recibimiento de la pareja causó alegría entre los mexicanos a su llegada al puerto de Veracruz, quienes organizaron un espontáneo festejo en su honor:

Sería la medianoche, cuando llegó portando antorcha una tropa de soldados mexicanos, así como profusión de músicos, [...] junto con una inmensa multitud [...] Se dejó oír, por último, el coro, acompañado de toda la orquesta [...] Un himno, compuesto para esta ocasión, y el cual recibimos en la mañana un ejemplar encuadernado con muy buen gusto, produjo un gran efecto [...] Se ejecutaron varias oberturas de las últimas óperas, y al final de lo que parecía el primer acto, y en medio de los ensordecedores aplausos de la multitud, Calderón [de la Barca] me hizo dar las gracias desde la ventana ¡en un magnífico español

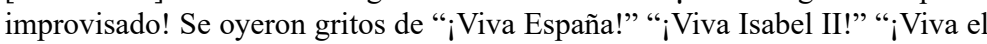
Ministro de España!”. Grandes y continuadas aclamaciones, Calderón [de la Barca] contestó con “¡Viva la República Mexicana!” "¡Viva Bustamante!” y la gritería fue tremenda. Por último vino un andaluz que se encontraba entre la multitud, lanzó un “¡Viva todo el mundo!” cuya agudeza provocó la hilaridad general. Después de repartir puros y ponche caliente, refresco muy adecuado en una noche tan fría, comenzó de nuevo la música, hasta que todo acabó con el himno nacional de España, con letra apropiada [...] el entusiasmo causado por la llegada del primer Ministro de España parece que va en aumento. Los cómicos preparan en honor suyo una función extraordinaria y los toreros una corrida también extraordinaria, con fuegos artificiales, pero todo esto no lo debéis tomar como una cortesía a la persona. Es tan solo una muestra de buena voluntad al primer representante de la Monarquía Española que trae de la Madre Patria el reconocimiento formal de la Independencia Mexicana. ${ }^{35}$

\section{La vida en México bajo una perspectiva de género}

El papel de las mujeres en las letras no ha sido del todo fácil, pues salvo excepciones muy notables, es prácticamente hasta finales del siglo XVIII, cuando pudieron ganarse la vida escribiendo. Entre las posibles explicaciones está, por ejemplo, una visión de su papel en la historia distanciada de la realidad, vista "más que un fenómeno de la naturaleza, más que un componente de la sociedad, más que una criatura humana, un mito". ${ }^{36}$ Esta concepción produce una mujer imaginada, la cual ha sido abundantemente retratada en la literatura:

Como una persona importantísima, polifacética: heroica y mezquina, espléndida y sórdida, hermosa y horrible a más no poder, tan grande como el hombre, más según algunos [...] en el terreno de la imaginación tiene la mayor importancia; en la práctica es totalmente insignificante [...] En la historia casi no aparece. En la literatura domina la vida de reyes y conquistadores [...] en la vida real sabía apenas leer, apenas escribir, y era propiedad de su marido. ${ }^{37}$

\footnotetext{
${ }^{35}$ Carta VI 41-43.

${ }^{36}$ Rosario Castellanos, Mujer que sabe latín.... (México, Fondo de Cultura Económica, 2009) 12.

${ }^{37}$ Virginia Woolf, Una habitación propia, (Barcelona, Seix Barral, 2008) 62-63.
} 
Esto es reforzado por el orden patriarcal de la sociedad, donde una figura dominante masculina tiene como prioridades vitales el conquistar, gobernar, "el creer que un gran número de personas, la mitad de la especie humana, son por naturaleza inferiores a él". Este orden ha sido sostenido por siglos, en los que "las mujeres han sido espejos dotados del mágico y delicioso poder de reflejar la silueta del hombre del tamaño del doble del natural", posición un tanto relativa, "porque si ellas se ponen a decir la verdad, la imagen del espejo se encoje; la robustez del hombre ante la vida disminuye". ${ }^{38}$

Por estas razones, en su tardío acceso a las letras, las mujeres se enfrentaron a ideas ancestrales en torno a su supuesta inferioridad intelectual y su naturaleza ajena al ejercicio intelectual: "Animal enfermo, diagnostica San Pablo. Varón mutilado, decreta Santo Tomás" ${ }^{39}$ Confinadas a la mera función biológica de la maternidad, la imagen de las mujeres ha sido mitificada hacia la exaltación, primero de la castidad, estado de pureza y periodo de preparación para la procreación, mientras que todo lo que rebase dicho paradigma es incomprendido, infravalorado, temido o condenado.

Si para un escritor su oficio ofrece incontables obstáculos, más complicado se presentaba para las mujeres. Para Virginia Woolf el principal reto era la carencia de "una habitación propia", algo impensable "a menos que los padres de la mujer fueran excepcionalmente ricos o muy nobles", de ahí que prácticamente solo "alguna gran dama aprovechara su relativa libertad y confort para publicar alguna cosa en su nombre arriesgándose a que la tomaran por un monstruo". ${ }^{40}$

Un caso de la Inglaterra decimonónica ilustra a la perfección lo dicho: James Edward Austen-Leigh, sobrino y redactor de las memorias de la escritora Jean Austen, quien relata: "Que pudiera realizar todo esto es sorprendente, pues no contaba con un despacho propio donde retirarse y la mayor parte de su trabajo debió hacerlo en la sala de estar común expuesta a toda clase de interrupciones" ${ }^{41}$ Por todo lo anterior, el papel que corresponde a las mujeres escritoras del siglo XIX, no obstante haber ya conquistado "espacio y visibilidad", presenta determinadas constantes, como lo señala Mercedes Arriaga y Carlo Bo:42

1. La indiferencia por parte de la crítica: Las producciones se quedan en el ámbito de lo privado (cartas, diarios, cuadernos de apuntes, libros de familia) y por ello, tienen poca repercusión y desdén de la crítica.

2. La falta de trasmisión de los textos femeninos: esto ha determinado, por una parte, la desconfianza de las escritoras hacia sí mismas por

\footnotetext{
${ }^{38}$ Woolf 51.

${ }^{39}$ Castellanos 20.

${ }^{40}$ Woolf, p. 71-73 y 81.

${ }^{41}$ Woolf, p. 93.

42 Mercedes Arriaga Flórez, Retórica de la escritura femenina, en Genara Pulido Tirado (coord.), La retórica en el ambito de las Humanidades : Seminario 2002-2003 (Jaén, Universidad de Jaén, 2003) www. escritorasyescrituras.com/cv/retorica.doc
} 
la escasez de modelos femeninos de referencia, pero, por otra, ha propiciado un auténtico trabajo de arqueología crítica rescatar a autoras del pasado.

3. La dificultad de las escritoras para afirmarse como tales: Las escritoras del pasado prefirieron géneros literarios menores destinados a un público prácticamente familiar y varias veces se escondieron tras la máscara del seudónimo masculino como fueron los casos de George Sand o George Elliot. "Estas dos circunstancias nos indican la incompatibilidad que existía entre ser mujer y ser escritora, el rechazo social hacia la mujer que dejaba el ámbito doméstico para entrar en la esfera de la cultura", lo que fomentó lo que Luisa Muraro llama "retórica de la incertidumbre" que consiste en la "captatio benevolentiae de los lectores a través de la presentación de un "yo" indigno, que entra en el espacio de la escritura pidiendo perdón por su osadía".

¿Qué hay pues, de todo esto en la obra de Fanny Calderón de la Barca? La obra es depositaria de una gran cantidad de virtudes, independientemente de los contenidos relatados en materia social, histórica, política y etnográfica, pues se trata del primer libro de viajes surgido de pluma femenina en el México independiente, pues para que la participación femenina dentro del mundo de las letras se viera como algo normal y hasta positivo, habría que esperar casi tres décadas. ${ }^{43}$

La inclusión de las mujeres en el espectro educativo mexicano es aún más tardía, pues según un testimonio de la época, “en México, más que en ninguna otra parte, es donde la mujer se encuentra casi exclusivamente reducida a la condición de criada de honor o, cuando más, de administradora gratuita". ${ }^{44}$ Este juicio se corrobora si se tiene en cuenta que, la Escuela Nacional Preparatoria, fundada bajo los preceptos positivistas en 1868 en el apogeo del liberalismo triunfante, no impedía formalmente en ninguno de sus estatutos el acceso de las mujeres a sus aulas; sin embargo, no sería sino hasta 1882 cuando se inscribiría la primera alumna. ${ }^{45}$ Para principios de la década de 1840, cuando se publica La vida en México, una obra que caracterizara tan específicamente a la sociedad mexicana escrita por una mujer, extranjera y no católica, era, no está de más decirlo, una auténtica osadía.

En la historia de las letras mexicanas, “a excepción de la conocida Décima Musa Sor Juana Inés de la Cruz (1651-1695), ningún otro nombre de mujer figuró en los anales de la literatura mexicana durante casi tres siglos". ${ }^{46}$ Aun así, hubo de enfrentarse a sus preceptores, las autoridades religiosas, obviamente masculinas. Ya

\footnotetext{
${ }^{43}$ Lourdes Alvarado (Transcripción y estudio introductorio) Educación y superación femenina en el siglo XIX: dos ensayos de Laureana Wright, Cuadernos del Archivo Histórico de la UNAM, (México, Universidad Nacional Autónoma de México, Centro de Estudios sobre la Universidad, 2005), p. 15

${ }^{44}$ Laureana Wright, Educación errónea de la mujer, en Alvarado 108.

${ }^{45}$ Alvarado 25

${ }^{46}$ Lucrecia Infante Vargas, De la escritura personal a la redacción de revistas femeninas. Mujeres y cultura escrita en México durante el siglo XIX, en Relaciones, no.113, Vol. XXIX, (Zamora, El Colegio de Michoacán, 2008).
} 
en la segunda mitad del siglo XIX, las mujeres con ansias de escribir, fueron objeto de señalamientos "entre quienes querían mejorar su educación y los que deseaban mantenerla en una «santa ignorancia» para que pudiera cumplir mejor con sus deberes hogareños como abnegada madre y esposa porque otra cosa sería ir «contra natura»". ${ }^{47}$ Apenas en 1839, mismo año de la llegada de la marquesa Calderón de la Barca a México, apareció la primera publicación dirigida a las mujeres, el Calendario de las Señoritas Mexicanas, publicado por el impresor Mariano Galván. ${ }^{48}$

\section{La mirada femenina de Fanny Calderón de la Barca}

A pesar de todo, Fanny Calderón de la Barca se vio favorecida por las circunstancias: la escuela para señoritas fundada por su madre en Estados Unidos estimuló su carácter literario desde temprana edad, pese a las condiciones, pues a decir de una observadora posterior,

...en los Estados Unidos nadie ríe ya de las mujeres que está al frente de grandes negociaciones comerciales, que dirige oficinas telegráficas, periódicos, que pleitea en los tribunales, que cura profesionalmente, y aún ni siquiera de la que monta en una máquina para conducir un tren, o de la que sube a los andamios de una casa para ejecutar un plano de arquitectura". ${ }^{49}$

Más aún, si a ello se agrega la amistad de Ticknor y Prescott, y la buena fortuna de haber contado siempre con el respeto a su formación intelectual y religiosa, así como el aliento a su actividad literaria por parte de Don Ángel, un hombre hecho a la usanza del Antiguo Régimen y, finalmente, la simpatía entre los mexicanos de la clase alta que la trataron durante su residencia en el país, quienes coincidieron en reconocerle como mujer de inteligencia y perspicacia notables. Por todo ello, la obra continúa erigiéndose, aun cumpliendo con las condiciones de la escritura femenina decimonónica arriba expuestas, como excepcional; así, el lector contemporáneo de $L a$ vida en México encuentra no solo:

una valiosa perspectiva sobre un período turbulento en la historia de México, sino que también marca su relato con una diferencia de género [pues] La narrativa de viajes se hibridiza a causa de una eficaz combinación entre una rigurosa documentación de sucesos políticos y la experiencia vivida; por eso el título La vida en México sugiere una curiosa mezcla entre aguda observación y mirada interior (insight). ${ }^{50}$

\footnotetext{
${ }^{47}$ Remedios Sánchez García, Las actitudes de las escritoras ante el intelectualismo inmovilista del Siglo XIX: Emilia Pardo Bazán frente a Carolina Coronado, en Elvira: Revista de estudios Filológicos, núm. 2 Alicante, (2001). http://www.cervantesvirtual.com/servlet/SirveObras/scclit/24693064013462495222202/ p0000001.htm

${ }^{48}$ Lucrecia Infante Vargas, Del “diario” personal al Diario de México. Escritura femenina y medios impresos durante la primera mitad del siglo XIX en México en Sara Beatriz Guardia (Compilación y edición), Escritura de la Historia de las Mujeres en América Latina. El retorno de las Diosas, (Lima, Centro de Estudios La Mujer en la Historia de América Latina CEMHAL, 2005), p. 285. Mariano Galván Rivera fue el más famoso impresor del siglo XIX mexicano, célebre por la publicación constante de sus calendarios, catecismos cívicos y gramáticas. El Calendario Galván se publica hasta la fecha en México.

${ }^{49}$ Laureana Wright, en Alvarado 53.

${ }^{50}$ Méndez (2002), En esta mirada interna no hay filtros intelectuales, sino impresiones directas, sinceras y
} 
La primera percepción es la ironía de con la que la autora enfatiza sus diferencias culturales con lo visto, apartándose del rigorismo o de la hostilidad de juicios de los libros de viajes de sus predecesores, diplomáticos y aventureros, y dotando a la lectura de una primera emoción: el humor seco anglosajón, fino y directo. Con todos estos antecedentes cabe preguntarse: pese a la forma de colección epistolar destinada a la comunicación familiar y el pretendido, y el tal vez intencionadamente mal logrado anonimato, ¿existía en la autora el deseo de dar a la luz pública sus experiencias en México? La respuesta es contundentemente afirmativa, como puede apreciarse en la siguiente carta de William Prescott a Charles Dickens:

El nombre de la bella autora que se esconde tras sus iniciales, por ser, en opinión de "su caro sposo", contrario a las reglas de la etiqueta diplomática, etc., el que el nombre de la esposa del Embajador (sic) se ostentase al frente de una obra que exhibe el mundo oficial y al país en el cual fueron residentes. Piensa que quizá no fuera bien visto en España. En consecuencia, sus editores de aquí han consentido en insertar un corto Prefacio firmado por mí, declarando que las cartas han sido publicadas por recomendación mía. ${ }^{51}$

La sutil -e inútil- velación de la identidad de la autora, no es tanto una decisión propia como una recomendación políticamente correcta para no alterar el incipiente equilibrio internacional recientemente establecido entre México y España. Además, gracias al apoyo del que se vale la autora, como los tratados sobre cuestiones históricas, geográficas y políticas de autores consagrados, más su propia prosa, culta, abundante en referencias a su propia intelectualidad, confirman que La vida en México siempre se pensó para ser editada.

La mirada femenina está también en la descripción de lo observado, pues pocas veces se había profundizado en la comida típica mexicana y en los sitios de recreación y ocio. Esta mirada, que ofreció por vez primera la apertura para la descripción de espacios públicos y privados, también atestiguó su participación como agente histórico en los movimientos armados y violentos que México vivía en ese entonces, ${ }^{52}$ en particular, el violento pronunciamiento militar de julio de 1840 en la capital que pretendía restaurar el sistema federal. En esta parte prioriza por sobre las causas de la violencia, el heroísmo de las mujeres, ya que "otorga valor a un tipo de comportamiento no valorizado y ni siquiera registrado en la historiografía oficial: la fuga de las mujeres de la escena del tiroteo para salvar a hijos, maridos u otros seres queridos". 53

\footnotetext{
subjetivas sobre hechos concretos, lo cual es esencial dentro de la perspectiva de género.

${ }^{51}$ Carta de Prescott a Charles Dickens, Boston, $1^{\circ}$ de diciembre de 1842. El Prefacio de la edición estadounidense está firmado el día 20 del mismo mes, en Teixidor, VIII. Se respeta la transcripción.

${ }^{52}$ Angélica Silva, Vida en México durante una residencia de dos años en ese país, de la Marquesa Calderón de la Barca, en Grafemas: Boletín electrónico de la AILFH, Febrero (2006). http://people.wku.edu/inma. pertusa/encuentros/grafemas/febrero_06/pdfs/silva.pdf

${ }^{53}$ Méndez, (2002)
} 
Dentro de ese realce de los méritos de grupos marginales, casi no visto en las letras hasta ese momento, también están aquellos que, por su condición social, ocuparon poca tinta en los impresos, a no ser retratados con meros fines recreativos; estos son

sirvientes, monjas, nodrizas, mercaderes, trabajadores de los plantíos, sirvientes, léperos, incluso hasta de los bandidos que intentaron asaltar su diligencia. Y no solo hace referencia a estos marginados, sino que aprovecha su relación con la aristocracia mexicana para describirla ya que su relación con ellos le da suficiente materia para hacerlo. ${ }^{54}$

Precisamente, esta condición de influyente dentro de una sociedad manejada por hombres políticos y militares, fue lo que la visibilizó, pero también le otorgó no pocos privilegios, tales como el acceso a ciertos lugares exclusivos de mujeres, los cuales antes nadie pudo retratar, como es el caso de los conventos y las escuelas para señoritas. Por último, su condición de extranjera limitó en un principio su comprensión en los temas de la estratificación social, étnica y de género mismo. Sin embargo, conforme la lectura avanza y el tiempo de residencia en México transcurre, la autora conoce y se familiariza con la sociedad y los lugares; así se percibe el cambio de su perspectiva, pues deja de ser la observadora que señala las incompatibilidades de los usos y costumbres mexicanos con los anglosajones, sino que, llegado el momento, participa de ellos como una más de los habitantes de la gran Ciudad de México.

En materia de religión, el hecho de ser protestante ${ }^{55}$ no obstó para participar gustosa del ceremonial católico y adentrarse en lugares vedados hasta para el feligrés habitual; sin embargo, en lo que corresponde a su impresión de ciertos ejercicios espirituales, su horror es patente, no tanto por su credo, sino por el tratamiento mismo del cuerpo humano en los ritos de Semana Santa, como los penitentes flagelantes y, en el caso de la vida monástica, no comprende la vida en clausura y se conduele de las religiosas que visita.

Con todo lo anterior, es evidente que, pese a las limitaciones propias de la época, impuestas a las mujeres dedicada al oficio de escribir, La vida en México de Fanny Calderón de la Barca, se sostiene ante el embate de la crítica de su tiempo y sale avante como la obra más rica y detallada sobre aspectos poco observados de la sociedad de la primera mitad del siglo XIX mexicano, pues más allá de las clasificaciones posibles, los recuerdos de la autora, es decir, la memoria, "recupera la historia a través de la escritura, que no solo permite restaurar las impresiones

\footnotetext{
${ }^{54}$ Méndez, (2002). Por fines recreativos se entiende la literatura costumbrista mexicana que ofrecía al lector visiones y descripciones de los tipos populares pero desde un punto de vista predominante mente estético: "Las costumbres y usos de la república, tan curiosos como interesantes, serán descritas en una serie de artículos con toda la exactitud [sic] que nos fuere posible, y sus láminas, ilustradas todas, o en su mayor parte, se procurará que tengan la corrección y la belleza necesarias para cumplir debidamente su objeto". El Museo Mexicano, 1843, en Amada Carolina Pérez Benavides, Actores, escenarios y relaciones sociales en tres publicaciones periódicas mexicanas del siglo XIX, en Historia Mexicana, año/vol. LVI, no. 004, (México, El Colegio de México, 2007) 1172.
}

${ }^{55}$ Silva 112. 
personales tal como fueron percibidas, sino que también recobra el tejido cultural de toda una época". ${ }^{56}$

\section{Conclusiones}

A diferencia de otros viajeros y diplomáticos, quienes describieron al México que vieron con interés científico o empresarial, o con desconcierto y hasta desprecio por no poder categorizar su realidad con sus propios conceptos, Fanny Calderón de la Barca no juzga sino aquello que, al principio, lastima sus sentidos, como el aspecto descuidado en aquella época del puerto de Veracruz o determinados sabores de alimentos y bebidas típicas de novedad para ella, como el pulque: "fue en este lugar donde por vez primera probé el pulque; y desde el primer sorbo deduje que así como el néctar era la bebida del Olimpo, podríamos conjeturar con justicia que Plutón ha de haber cultivado el maguey en sus dominios". ${ }^{57}$

En su percepción de las prácticas religiosas del catolicismo en México, si bien las aborda en su generalidad con respeto e interés, al grado de ser la primera persona en entrar y registrar la vida conventual femenina del siglo XIX, le resultará imposible matizar su espanto ante las flagelaciones de los disciplinantes de Semana Santa. Fanny Calderón de la Barca sustenta sus impresiones tanto en la teoría como la práctica: posee una amplia cultura que se incrementa a medida que consulta más fuentes y convive tanto con los personajes más trascendentales, como los expresidentes y veteranos de la Independencia o los políticos de la República, así como con la gente los más cotidiana; prueba de buena gana los alimentos nuevos que se le ofrecen y los juzga positiva o negativamente a partir de la experiencia, admira los paisajes y monumentos y traduce la impresión en términos de su propia cultura.

Todo aquí nos recuerda al pasado: el de los conquistadores españoles, que parecían construir para la eternidad, dejando en sus obras la huella de su carácter duro, grave y religioso [...] Es el presente el que parece un sueño y un desvanecido reflejo del pasado. Todo está en decadencia y todo se va esfumando, y tal parece que los hombres confían en un futuro ignoto que quizás nunca verán. ${ }^{58}$

Las buenas intenciones de la obra no la exentan de un inicial carácter etnocentrista, propio de todo observador extranjero, que trata de entender el mundo que se le presenta solo en los términos que éste puede entender, pero en el caso de Fanny, a medida que avanza el tiempo de su vida en México, se irá matizando, prueba de ello es la empatía con varios aspectos de la cultura mexicana y la tristeza sincera que le produce abandonar el país. Obra fundamental en varios sentidos, gracias a su descripción de personajes y lugares, paisajes y costumbres, ritos religiosos y cívicos

\footnotetext{
${ }^{56}$ Gloria Hintze, Memoria, historia y ficción en la escritura femenina del siglo XIX. La ciudad heroica de Rosario Puebla de Godoy (Cuyo, Universidad Nacional de Cuyo. Facultad de Filosofía y Letras, 2004). http://bdigital.uncu.edu.ar/objetos_digitales/486/Hintze.CILHA.pdf

${ }^{57}$ Carta V 33.

${ }^{58}$ Carta XXXVIII 267-268.
} 
$\mathrm{y}$, por otra parte, por los fragmentos de la vida de una mujer que se abrió paso en una cultura diametralmente opuesta a la suya, Fanny Calderón de la Barca dejó en La vida en México un abundante caudal de información para diversas disciplinas de estudio, que merece una mayor difusión que las actuales ediciones y reseñas.

\section{Bibliografía}

\section{Fuentes primarias}

\section{Libros}

Calderón de la Barca, Madame. La vida en México durante una residencia de dos años en ese país, México, Editorial Porrúa, colección "Sepan cuantos..." Núm. 74, 1997.

\section{Fuentes secundarias}

\section{Libros}

Castellanos, Rosario. Mujer que sabe latín..., México, Fondo de Cultura Económica, 2009.

Costeloe, Michael P. La República central en México, 1835-1847. “Hombres de bien” en la época de Santa Anna, México, Fondo de Cultura Económica, 2000.

Esadile, Charles. El levantamiento español, en La quiebra del liberalismo (18081939), Barcelona, Crítica, 2001.

Falcón, Romana. Las rasgaduras de la descolonización, México, El Colegio de México, 1996.

Gran Historia de México Ilustrada. México, Planeta DeAgostini, CONACULTA, INAH, 2002.

Guardia, Sara Beatriz (Edición y compilación). Viajeras entre dos mundos, Mato Grosso do sul, Universidade Federal da Grande Dourados, 2012.

Guardia Sara Beatriz (Compilación y edición). Escritura de la Historia de las Mujeres en América Latina. El retorno de las Diosas, Lima, Centro de Estudios La Mujer en la Historia de América Latina CEMHAL, 2005.

Historia General de México (Versión 2000). México, El Colegio de México, 2009.

Palomar de Miguel, José. Diccionario de México. México, Editorial Trillas, 2005. 
Sánchez García, Remedios, Las actitudes de las escritoras ante el intelectualismo inmovilista del Siglo XIX: Emilia Pardo Bazán frente a Carolina Coronado. http:/www.cervantesvirtual.com/servlet/SirveObras/ scclit/24693064013462495222202/p0000001.htm

Silva, Angélica. Vida en México durante una residencia de dos años en ese país, de la Marquesa Calderón de la Barca, Grafemas: Boletín electrónico de la AILFH. http://www.pRodenasanam.edu/dept/modlang/grafemas/febrero_06/silva.html

Woolf, Virginia. Una habitación propia. Barcelona, Seix Barral, 2008.

\section{Artículos de revistas}

Alvarado, Lourdes. "Educación y superación femenina en el siglo XIX: dos ensayos de Laureana Wrigh". Cuadernos del Archivo Histórico de la UNAM. Universidad Nacional Autónoma de México, Centro de Estudios sobre la Universidad, 2005.

Alloatti, Norma. "Narradoras de la ventura: viajeras del siglo XIX en la colección Lermon" Revista Electrónica de Fuentes y Archivos, Córdoba, Centro de Estudios Históricos "Prof. Carlos S. A. Segreti” año 5, 5, (2014).

Figueroa, Raúl. “Ángel Calderón de la Barca, diplomático español (1790-1861). Notas biográficas, Estudios”. Filosofía-Historia-Letras, Otoño 1990.

Flores, Oscar, Frances Erskine Inglis (Madame Calderón de la Barca). "The Attaché in Madrid; or, Sketches of the Court of Isabella II. Traslated from German”. Nueva York, Casa Appleton, 1856. http://ocw.udem.edu.mx/cursos-de-profesional/ historia-del-mexico-independiente/08calderondelabarca.pdf

Guardia, Sara Beatriz. "Un acercamiento a la historia de las mujeres”. Revista de Humanidades 10, Instituto Tecnológico y de Estudios Superiores de Monterrey, 2001.

Infante Vargas, Lucrecia. "De la escritura personal a la redacción de revistas femeninas. Mujeres y cultura escrita en México durante el siglo XIX”. Relaciones, 113, XXIX, Zamora, El Colegio de Michoacán, Invierno 2008.

Landavazo, Marco Antonio. "Imaginarios encontrados: El antiespañolismo en los siglos XIX y XX, Tzintzuntzan”. Revista de Estudios Históricos, en Universidad Michoacana de San Nicolás de Hidalgo, Morelia, 42 (2005).

Pérez Benavides, Amada Carolina "Actores, escenarios y relaciones sociales en tres publicaciones periódicas mexicanas del siglo XIX”. Historia Mexicana, LVI, 4, El Colegio de México, (2007). 
Anuario de Historia Regional y de las Fronteras, vol. $26 n .^{\circ} 2$

\section{Publicaciones en internet}

www.escritorasyescrituras.com/cv/retorica.doc

http://www.bibliojuridica.org/libros/1/252/8.pdf

http://www.jornada.unam.mx/2010/05/25/index.php?section=cultura\&article=a08n1cul http://www.iih.unam.mx/moderna/ehmc/ehmc02/008.html

http://biblioteca.itam.mx/estudios/estudio/letras22/notas1/sec_1.html

http://www.lehman.cuny.edu/ciberletras/v05/mendez.html 